Document downloaded from:

http://hdl.handle.net/10251/103254

This paper must be cited as:

Pruna, A.; Pullini, D.; Busquets, D. (2013). Influence of synthesis conditions on properties of green-reduced graphene oxide. Journal of Nanoparticle Research. 15(5):1-11. doi:10.1007/s11051-013-1605-6

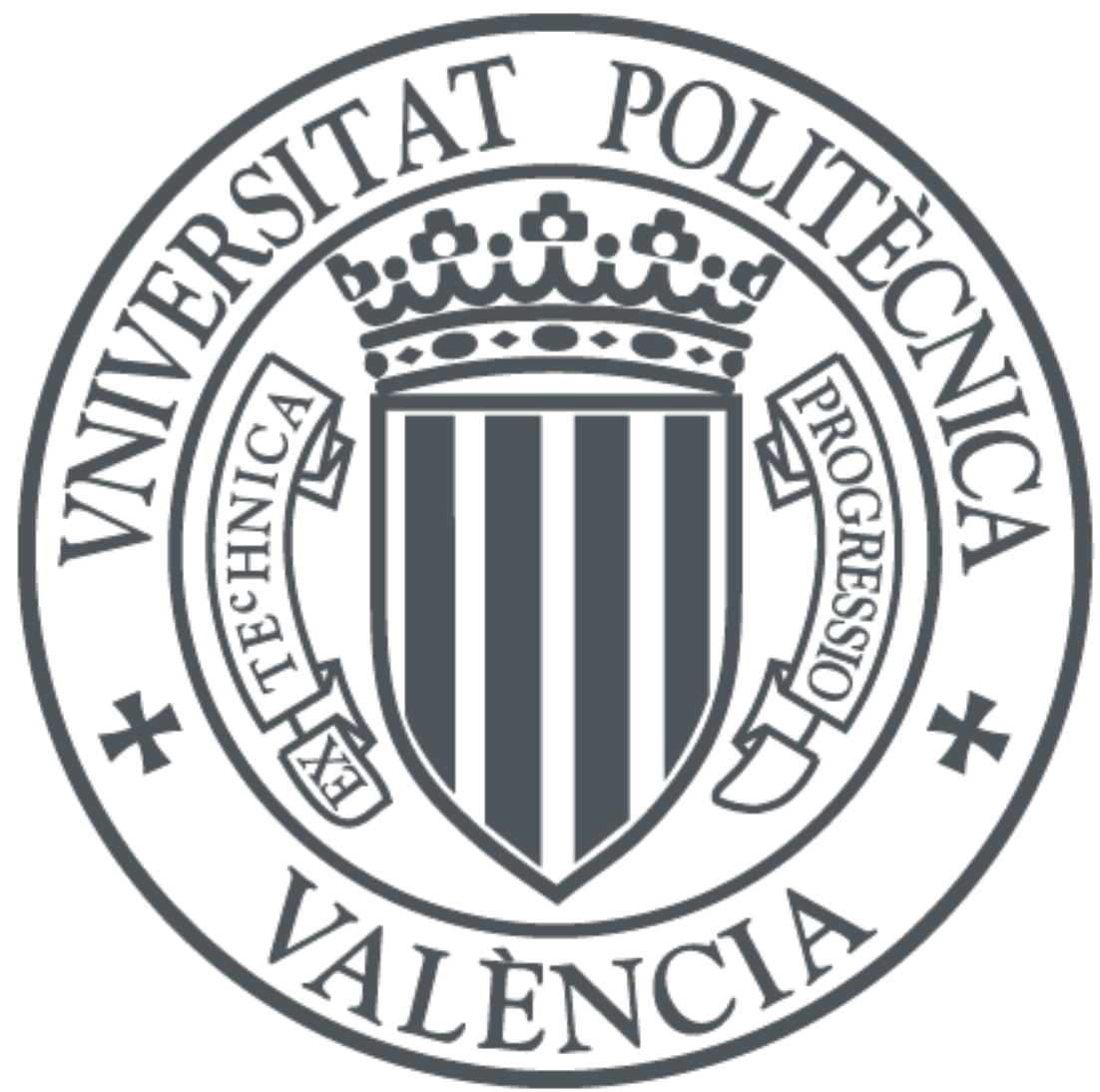

The final publication is available at

https://doi.org/10.1007/s11051-013-1605-6

Copyright Springer-Verlag

Additional Information 


\title{
Influence of synthesis conditions on properties of green-reduced graphene oxide
}

\author{
A. Pruna $\cdot$ D. Pullini $\cdot$ D. Busquets
}

\begin{abstract}
Green reduction of graphene oxide (GO) was performed using ascorbic acid (AA) in the presence of poly(sodium 4-styrenesulfonate), which resulted in reduced graphene oxide (PSS-rGO) with excellent solubility and stability in water. Large rGO sheets of $4 \mu \mathrm{m}^{2}$ area and 1.1-nm thickness were obtained. The measurements showed that noncovalent functionalization with PSS molecules prevented rGO from aggregation. The parameters of graphite oxidation process and AA:GO w/w ratio were evaluated, and the obtained results showed that the properties of
\end{abstract}

Electronic supplementary material The online version of this article (doi:10.1007/s11051-013-1605-6) contains supplementary material, which is available to authorized users.

A. Pruna $(\square)$

Institute of Materials Technology, University Politécnica of Valencia, Camino de Vera s/n, 46022 Valencia, Spain e-mail: ai.pruna@gmail.com; apruna@itm.upv.es

\section{A. Pruna}

University of Bucharest, 405 Atomistilor Street,

077125 Bucharest, Romania

D. Pullini

Fiat Research Centre, 50 Torino Street, 10043 Orbassano, Italy

D. Busquets

Department of Mechanical and Materials Engineering, University Politécnica of Valencia, Camino de Vera s/n, 46022 Valencia, Spain the reduced material (PSS-rGO) can be tailored by proper selection and adjustment of these parameters.

Keywords Graphene oxide $\cdot$ Reduction ·

Functionalization $\cdot$ Poly(sodium 4-styrenesulfonate)

\section{Introduction}

Recently, the scientific community devoted a great interest to graphene research as it exhibits excellent inplane mechanical, thermal, electrical, and optical properties (Wu et al. 2007; Lee et al. 2008; Li and Kaner 2008; Nair et al. 2008) thanks to which it accounts not only for fundamental research but also for device applications such as energy storage devices, optoelectronic devices, chemical sensors, and drug delivery (Yin et al. 2010; Patil et al. 2009; Bae et al. 2010; Choi et al. 2010).

As for the production methods developed so far, one can mention liquid-phase exfoliation of graphite (Hernandez et al. 2008), chemical vapor deposition (Park et al. 2010), arc-discharge (Subrahmanyam et al. 2009), large growth or self-assembly approach ( $\mathrm{Li}$ et al. 2009), chemical reduction of graphene oxide (GO) (Li et al. 2008), laser-induced reduction (Kumar et al. 2011a; Kumar et al. 2012), laser unzipping of CNTs (Kumar et al. 2011b), or laser-induced exfoliation of graphite (Maitra et al. 2012). The increased interest in graphene-based nanocomposites generated 
requirements of large scalability and homogeneous distribution of graphene sheets for which the chemical conversion from graphite oxide can be accounted besides the fact that it provides with a more efficient bulk production pathway to incorporate graphene sheets into hybrids and also with material availability at low cost which represents a mandatory aspect in this field (Kuilla et al. 2010). The major advantage of chemical reduction method over the other ones is that it is straightforward to synthesize high yield of monolayers of $\mathrm{GO} /$ reduced graphene oxide $(\mathrm{rGO})$, while the chemical composition of GO is easily engineered allowing tenability of rGO-based devices. The average size of GO sheets can be tailored by oxidation procedure (Zhang et al. 2009), while rGO dispersibility in various solvents can be controlled by functionalization procedures (Kuila et al. 2012).

The oxygen-containing functional groups introduced on both the edge and basal plane of the nanosheets by oxidation (Hontoria-Lucas et al. 1995) can be removed by further chemical reduction of GO, and aromatic graphene network can be partially restored, while the strong $\pi-\pi$ interaction between the nanosheets of rGO will cause its irreversible agglomeration. Nevertheless, the presence of anionic polymers such as poly(sodium 4-styrenesulfonate) (PSS) have been shown to prevent rGO agglomeration upon reduction by hydrazine (Stankovich et al. 2006). Oweing to the environmental hazard involved, this highly investigated reducing agent (Park et al. 2011) should be avoided in the large-scale production of rGO, and therefore it does not represent the subject of this study. Instead, the present article is intended to provide an extensive study of the properties of rGO materials obtained by reducing the GO with environmentally friendly agent.

Among the green-reducing methods employed for synthesis of rGO, one can find the use of melatonin, glucose, bovine serum albumin, bacteria, or polyphenols of green tea (Akhavan et al. 2011; Akhavan and Ghaderi 2012; Akhavan et al. 2012) or methods such as flash photo reduction, hydrothermal and solvothermal reductions, and catalytic and photocatalytic reductions (Cote et al. 2009; Zhou et al. 2009). Ascorbic acid (AA) has been already successfully employed as substitute for hydrazine (Zhang et al. 2010). The reduced material can reach a C/O ratio of about 12.5 and a conductivity of 77 $\mathrm{S} \mathrm{cm}^{-1}$ (Fernandez-Merino et al. 2010). Nevertheless, considering the facts that the reported rGO material still presented agglomerates in aqueous solutions and that the preservation of the unique electronic properties of $\mathrm{rGO}$, and minimization of the negative impact on the structure of rGO is possible by noncovalent functionalization of rGO through $\pi-\pi$ interactions (Bai et al. 2009), the effect of PSS on the properties of rGO material was considered in this study, to offer a solution for the synthesis of stable aqueous dispersion of greenreduced GO.

A systematic investigation on the effect of graphite oxidation conditions and of both noncovalent functionalization and reduction of GO on the properties of the novel graphene materials is presented. The advantages of the approach presented here over the previous strategies, such as cheapness, simplicity, environmentally friendly and the high dispersion of the obtained product, make it rather attractive for the larger-scale fabrication of dispersed graphene for practical applications. Although the fabrication of the most graphene-based devices still requires great effort and the ability to achieve complete graphene dispersion in the matrix of choice influences greatly the composite applications, the results shown in this study prove that this novel PSS-rGO material could be implemented in graphene-based composites.

\section{Experimental}

\section{Materials}

Natural graphite powder 200 mesh $(99.9995 \%)$ was purchased from Alfa Aesar. All other reagents were of analytic grade and used as received. All aqueous solutions were prepared with double-distilled water.

Preparation of GO

GO was prepared by oxidizing the graphite in two different ways. The first mode (method A) was based on a modified Hummers method as described previously (Fan et al. 2009). Basically, 1 g graphite powder was oxidized with $25 \mathrm{~mL} \mathrm{H}_{2} \mathrm{SO}_{4} 98 \%$ and $3 \mathrm{~g}$ $\mathrm{KMnO}_{4}$ at $35{ }^{\circ} \mathrm{C}$ for $3 \mathrm{~h}$. Further, the mixture was cooled to room temperature and diluted with $400 \mathrm{~mL}$ deionized water maintaining the temperature below $90{ }^{\circ} \mathrm{C}$. Successively, $30 \% \mathrm{H}_{2} \mathrm{O}_{2}$ was added to the mixture. Further, the mixture was filtered and purified with $\mathrm{HCl}\left(9: 1 \mathrm{v} / \mathrm{v}\right.$ in $\left.\mathrm{H}_{2} \mathrm{O}\right)$, and then washed with 
deionized water till neutral $\mathrm{pH}$ was reached. The obtained product was subjected to a drying process at $50{ }^{\circ} \mathrm{C}$ for $24 \mathrm{~h}$. A variation of this procedure (method B) was used to study the effect of oxidation process on reduction of GO. By this latter method, the graphite was oxidized for $2 \mathrm{~h}$ in a $150-\mathrm{mL}$ mix of $\mathrm{H}_{2} \mathrm{SO}_{4}: \mathrm{H}_{3} \mathrm{PO}_{4}(6: 1 \mathrm{v} / \mathrm{v})$ and $6 \mathrm{~g} \mathrm{KMnO}_{4}$. In order to obtain the corresponding $\mathrm{GO}$ material, each product was dispersed in water by sonication.

\section{Chemical reduction of GO}

As seen in Fig. 1, a typical procedure for chemical conversion of PSS-GO into PSS-rGO requires the dispersion of graphite oxide $\left(0.1 \mathrm{mg} \mathrm{mL}^{-1}\right)$ in water (by sonication treatment for $1 \mathrm{~h}$ ) to achieve highly exfoliated GO. PSS was further used to functionalize the GO under sonication for $1 \mathrm{~h}$. AA was added to the PSSGO dispersions, and the resultant solution was kept for $24 \mathrm{~h}$ at room temperature, under mechanical stirring. The obtained product was isolated by filtration, washing with water and drying in vacuum at $50{ }^{\circ} \mathrm{C}$ for $24 \mathrm{~h}$.

\section{Characterization methods}

Absorbance UV-Vis spectra were recorded using a Lambda 35 (Perkin Elmer) spectrophotometer. Energy-dispersive analysis (EDAX) was performed on a JEOL microscope. Thermogravimetric analysis (TGA) was conducted with a Q50 (TA Instruments) thermal analyzer under nitrogen flow at a scanning rate of $10{ }^{\circ} \mathrm{C} \mathrm{min}^{-1}$. The FTIR spectra were acquired on a Perkin Elmer FTIR Spectrum BX spectrometer in ATR mode. The X-ray diffraction (XRD) spectra were taken on a D2 Phaser (Bruker) diffractometer using $\mathrm{Cu}$ $\mathrm{K} \alpha$ radiation and a voltage of $30 \mathrm{kV}$. Raman spectra were acquired on inVia Renishaw spectrometer with 514.5-nm wavelength of incident laser light. The investigation of the morphology had been performed by transmission electron microscopy (TEM) and scanning electron microscopy (SEM) using a TECNAI-10 (Philips) microscope and JEOL 6300, respectively. Atomic Force micrographs (AFMs) were obtained using a Bruker microscope operating in tapping mode. The samples previously dispersed in ethanol were drop-cast on freshly cleaved mica (or gold substrates) and dried at room temperature.

\section{Results and discussion}

Optical analysis

Yellow-brown aqueous dispersions were obtained from both types of the as-prepared GO materials, see Fig. 2a. The reduction of GO was observed for different reaction time; nevertheless, in this study, only the 24-h-reduced material is characterized. The colour change of the reaction mixture from brown to black was assigned to successful synthesis of rGO by the partial restoration of the $\pi$ network and electronic conjugation within reduced sheets (Li et al. 2008). The image in Fig. 2a revealed higher hydrophilicity for $\mathrm{rGO}_{\mathrm{B}}$ material than $\mathrm{rGO}_{\mathrm{A}}$, which could be explained by the presence of a higher amount of residual oxygen functional groups. It is evident that PSS assisted the aqueous dispersibility of $\mathrm{rGO}_{\mathrm{A}}$ while for $\mathrm{rGO}_{\mathrm{B}}$ the image is inconclusive. Further investigations are presented in the latter sections to help in assessing the PSS effect on differently oxidized GO materials.

Further, different AA:GO w/w ratio values were evaluated, and the stability of dispersions was monitored in time. The results showed that more agglomerates were produced as the AA:GO ratio increased, see Fig. 2b. This is explained by the fact that increasing the amount of reducing agent will remove more functional groups from the GO sheets, rendering the rGO more hydrophobic. The solutions precipitated over long period of time (6 months); therefore functionalization of $\mathrm{rGO}$ was required as a measure to

Fig. 1 The schematics of PSS-rGO synthesis

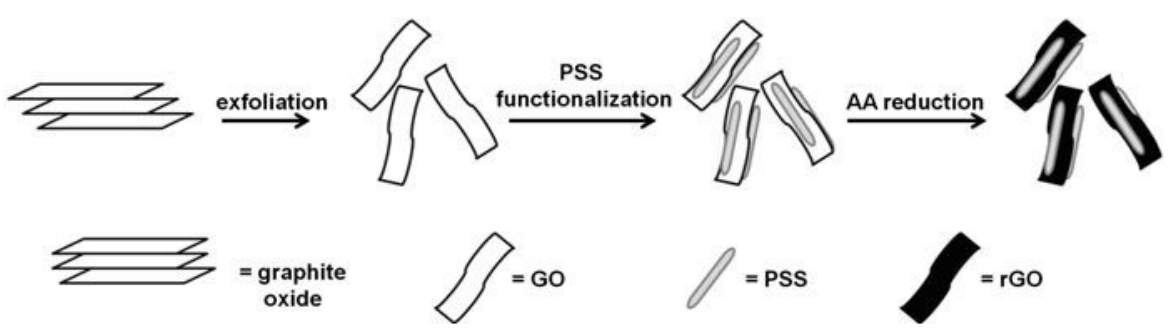


Fig. 2 Digital photographs of: a GO, rGO and PSS-rGO aqueous dispersions for batches $\mathrm{A}$ and $\mathrm{B} \mathbf{b} \mathrm{rGO}_{\mathrm{A}}$ aqueous dispersions as a function of AA:GO w/w ratio and $\mathbf{c}$ PSS- $-\mathrm{rGO}_{\mathrm{A}}$ aqueous dispersions as a function of PSS:GO ratio (for AA:GO w/w ratio equal to $20: 1)$. b, c images were taken after 6-months

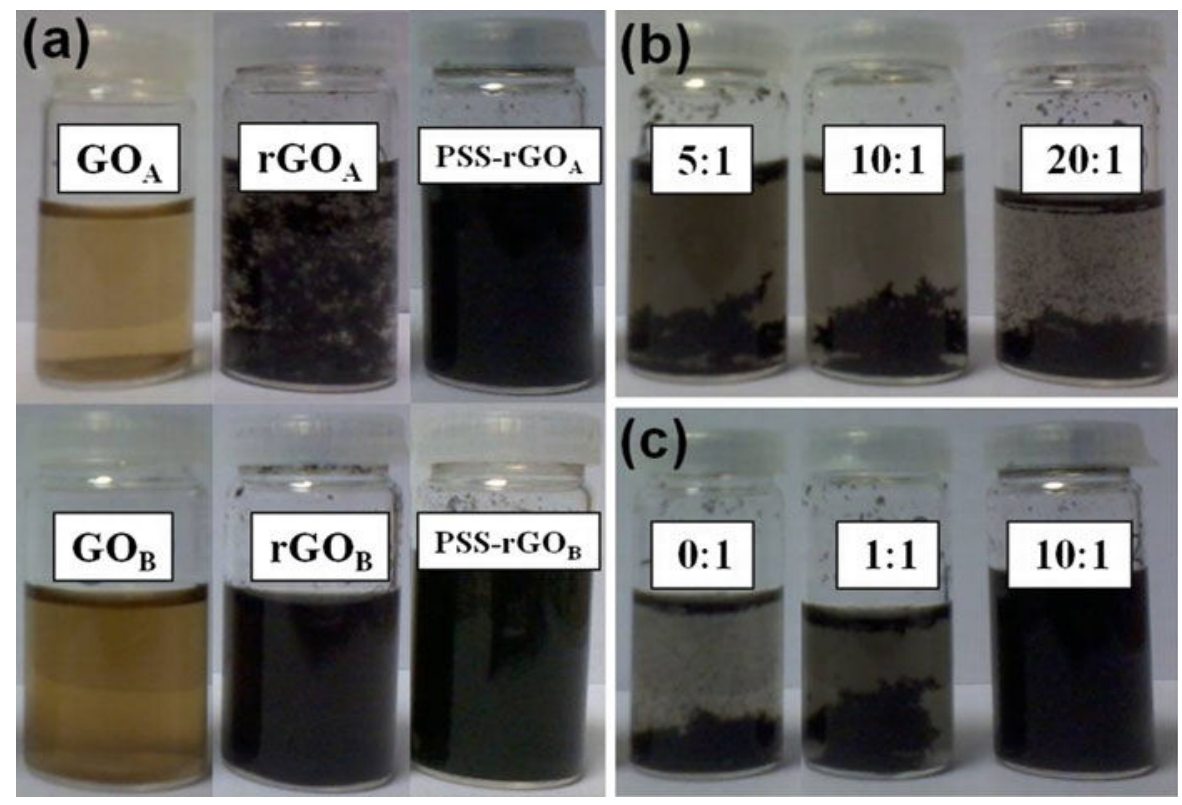

increase the stability and dispersion. As seen from Fig. 2c taken after the same period of time, PSS functionalization resulted in more dispersed aqueous solutions of reduced material with PSS:GO w/w ratio, confirming the successful attachment of the increasing number of PSS molecules.

\section{XRD measurements}

As evidenced from XRD spectra in Fig. 3, raw graphite showed a crystal structure with an interlayer spacing of $0.338 \mathrm{~nm}$. The typical (002) diffraction peak was shifted at $2 \theta$ values in the range of $10.5-11.5^{\circ}$ for $\mathrm{GO}_{\mathrm{A}}$ and $\mathrm{GO}_{\mathrm{B}}$ materials, corresponding to an interlayer spacing of 0.83 and $0.66 \mathrm{~nm}$, respectively, which translates to a less-expanded type B material. Such large spacing values can be explained by the presence of intercalating oxygen-containing functionalities (Buchsteiner et al. 2006) and also by structural defects ( $s p^{3}$ bonding) in the sheet. The removal of functional groups by chemical reduction reflected in the up-shift of the (002) peak position and interlayer spacings of $0.44-0.48 \mathrm{~nm}$, in addition to the appearance of a small shoulder at higher $2 \theta$ position due to partial restoration of conjugated $s p^{2}$ carbon network. The higher spacing for $\mathrm{rGO}_{\mathrm{B}}$ is in agreement with the enhanced dispersibility observed in Fig. 2a. This suggests a lower reduction degree for $\mathrm{rGO}_{\mathrm{B}}$ due to impeded diffusion of reducing agent into a $\mathrm{GO}$

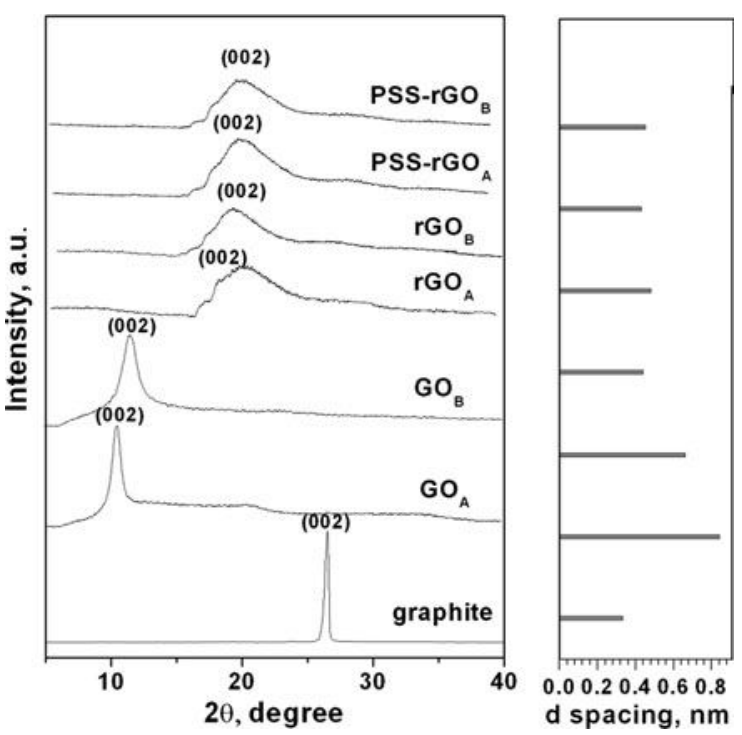

Fig. 3 XRD patterns for graphite, GO, rGO and PSS-rGO materials

material with narrower interlayer distance. Regarding the reduced functionalized materials, the PSS molecules would be expected to be inserted into the graphite layers enhancing the dispersion and favoring the reduction, the fact that would contribute to some expansion of the interlayer spacing. Nevertheless, the obtained (002) interlayer spacings were slightly smaller than those obtained in the absence of PSS $(0.43$ and $0.45 \mathrm{~nm})$ suggesting the assistance of PSS in 
Fig. 4 FTIR spectra of GO, rGO and PSS-rGO materials for a oxidation conditions A and $\mathbf{b}$ oxidation conditions $\mathrm{B}$

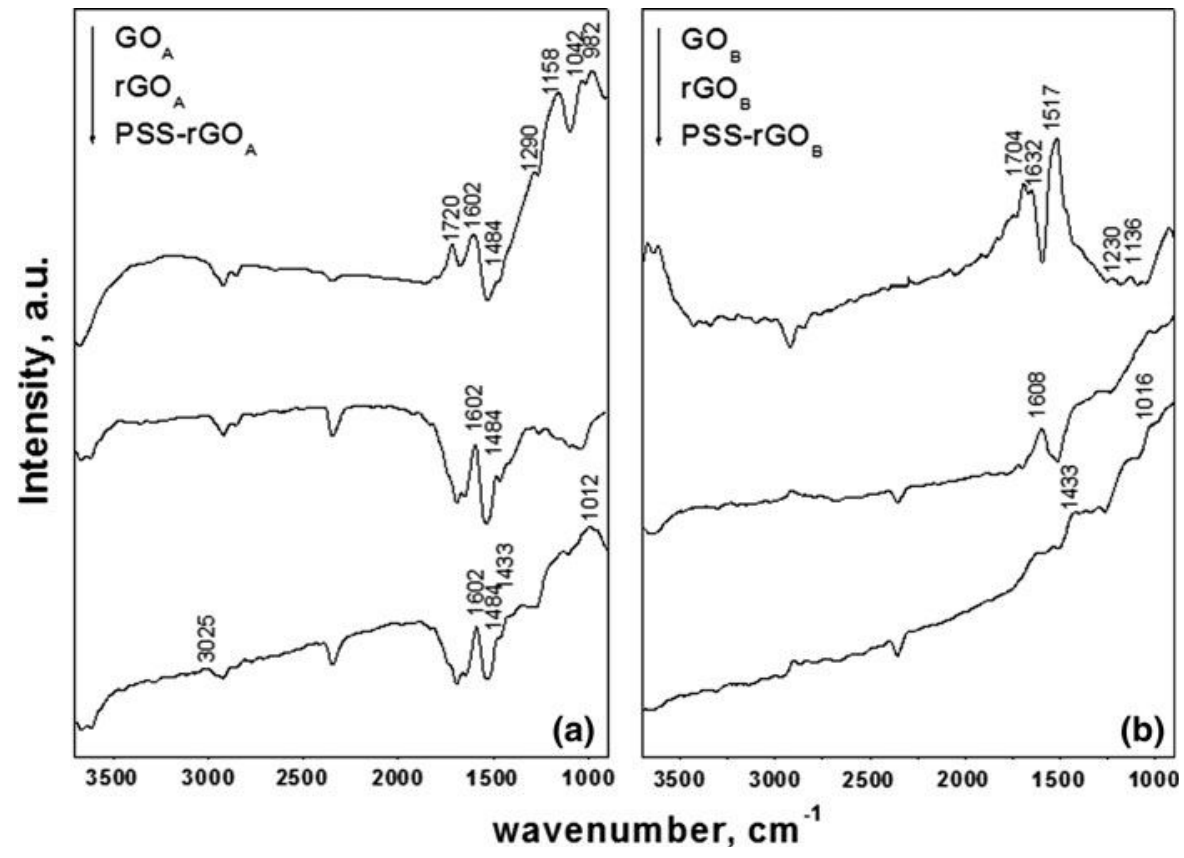

reduction process and possible interactions upon its intercalation that could result in distance contraction as the interactions between GO layers are dominated by hydrogen bonding of functional groups and trapped molecules between the layers (Park et al. 2008).

\section{FTIR measurements}

Figure 4 shows the typical FTIR spectra of GO, rGO, and PSS-rGO materials. The presence of oxygen groups in $\mathrm{GO}_{\mathrm{A}}$ was confirmed by the peaks observed at $1,720(\mathrm{C}=\mathrm{O}$ stretching vibration band from carbonyl and carboxyl groups), 1,484 (O-H bending vibrations from hydroxyl groups), 1,290 (C-OH stretching vibration), 1,158 (C-O-C breathing vibrations from epoxy groups), 1,042 (C-OH vibrational mode), and at $982 \mathrm{~cm}^{-1}$ (stretching vibration bands from epoxy groups) (Park et al. 2009, Xu et al. 2008). The spectra show another peak at $1,602 \mathrm{~cm}^{-1}$ which was attributed to $\mathrm{C}=\mathrm{C}$ stretching vibrations from unoxidized graphitic domains or to ester groups (Mei and Ouyang 2011), and a broad band at $3,000-3,500 \mathrm{~cm}^{-1}$ attributed to the adsorbed bound water (Wu et al. 2011). The increased peak intensity of $\mathrm{C}=\mathrm{C}$ stretching upon reduction suggests the recovery of $s p^{2}$ lattice, while the markedly weaker bands of adsorbed water and oxygen groups confirm their removal. Nevertheless, the $\mathrm{O}-\mathrm{H}$ bending mode from hydroxyl groups was still observed in reduced material. The appearance of peaks at $3025,1602,1433$ and $1012 \mathrm{~cm}^{-1}$ confirmed the attachment of PSS molecules (Wu et al. 2011). Figure $4 \mathrm{~b}$ reveals different compositions of GO materials as a function of oxidation parameters: the band at 3,000-3,500 is markedly weaker for the type B materials, and the intensity of the $\mathrm{O}-\mathrm{H}$ band from hydroxyl groups at $1,517 \mathrm{~cm}^{-1}$ is markedly stronger than the other bands of oxygen groups in $\mathrm{GO}_{\mathrm{B}}$ and with respect to $\mathrm{GO}_{\mathrm{A}}$, respectively. The removal of oxygen functionalities is confirmed by the corresponding weaker bands in reduced materials, while the strong band at $1,608 \mathrm{~cm}^{-1}$ suggests the recovery of $s p^{2}$ lattice.

A simple elemental analysis run by EDAX measurement in randomly selected areas of each material showed the increase of $\mathrm{C} / \mathrm{O}$ atomic ratio in rGO materials, see Fig. 5. Since light element quantitative analysis is not reliable by EDAX and taking into account the inhomogeneity of the samples, these results show only qualitatively the efficiency in removing the oxygen-containing functionalities in GO by reduction with $\mathrm{AA}$, in the absence and the presence of PSS, attachment of which was confirmed by the presence of sulfur and sodium elements. 


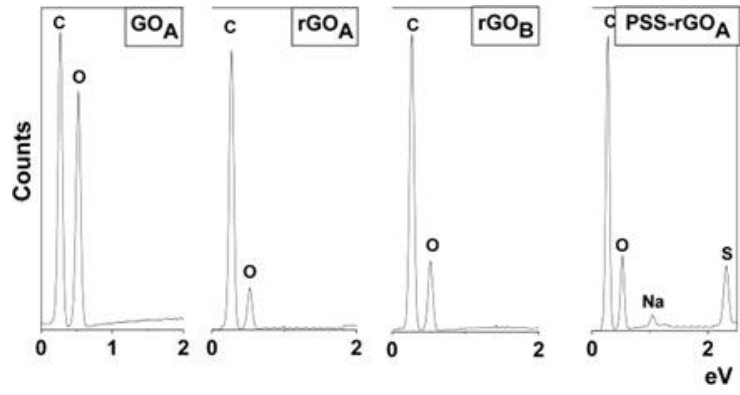

Fig. 5 EDAX analysis of GO, rGO and PSS-rGO

Thermogravimetric analysis

Further, the thermal behaviors of graphite, GO, and rGO powders were studied by TG analysis as shown in Fig. 6. Graphite weight loss was about $5 \%$ below $700{ }^{\circ} \mathrm{C}$ as reported in previous researches. GO materials showed much lower thermal stability due to the reduced van der Walls interaction. Following the initial weight loss of about $15 \%$ at $100{ }^{\circ} \mathrm{C}$ ascribed to the removal of loosely bound or adsorbed water and gas molecules, the onset temperature was lowered due to pyrolysis of the oxygen-containing functional groups, yielding $\mathrm{CO}, \mathrm{CO}_{2}$, and steam. That is, the $\mathrm{GO}_{\mathrm{A}}$ showed an abrupt mass loss $(\sim 35 \%)$ in the range of $100-200{ }^{\circ} \mathrm{C}$ followed by a steady one $(15 \%)$ in the range of $200-300{ }^{\circ} \mathrm{C}$, assigned to decomposition of labile oxygen functional groups. There is also another large loss (about $20 \%$ ) in the range of $700-900{ }^{\circ} \mathrm{C}$ assigned to the removal of more stable oxygen functionalities. On the other hand, $\mathrm{GO}_{\mathrm{B}}$ exhibited smaller weight losses in the 200-300 and 500-700 ${ }^{\circ} \mathrm{C}$ temperature ranges. These results confirm the XRD ones and indicate that overall amounts of oxygen functionalities, their types, and distributions in the GO materials can be tailored by appropriate graphite oxidation parameters in agreement with earlier finding that harsher conditions and longer oxidation times result into an increased ratio of epoxides to hydroxyl groups (Boukhvalov and Katsnelson 2008; Jeong et al. 2008). In the same time, the differences observed indicate a variation in the number of GO layers as shown to markedly affect the decomposition of oxygen groups, e.g., ketones and carboxyls remain above $400{ }^{\circ} \mathrm{C}$, and they are removed after a $650{ }^{\circ} \mathrm{C}$ in three-layer GO materials (Acik et al. 2011).

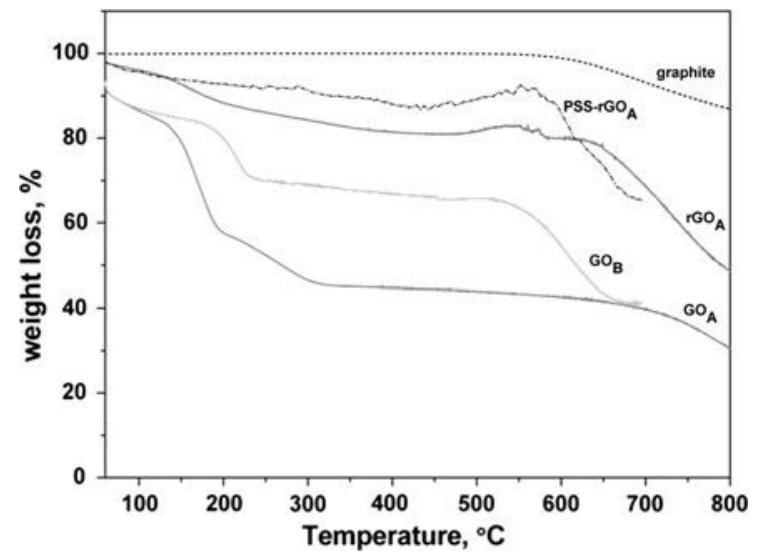

Fig. 6 TG plots for graphite, $\mathrm{GO}, \mathrm{rGO}_{\mathrm{A}}$ and $\mathrm{PSS}-\mathrm{rGO}_{\mathrm{A}}$

As a confirmation of successful reduction, the $\mathrm{rGO}_{\mathrm{A}}$ material showed about $7 \%$ weight loss at $100{ }^{\circ} \mathrm{C}$, indicating less amount of adsorbed water, see Fig. 6. Moreover, the thermal stability of rGO is closer to pristine graphite, and no abrupt mass loss was found in the temperature range of $170-250{ }^{\circ} \mathrm{C}$, indicating the success of the reduction process by the removal of labile oxygen-containing groups. In comparison to GO behavior, the lower weight loss observed in higher temperature range indicates also the partial removal of the more stable functionalities in the rGO material.

Further, when PSS was added, the thermal stability in the low temperature range increased with respect to the material obtained in its absence. Nevertheless, at high temperature values around $550{ }^{\circ} \mathrm{C}$, a weight loss was still registered, and it was higher than that observed in the absence of PSS confirming the successful attachment of PSS molecules to reduced GO materials, and the XRD finding of possible interactions upon PSS intercalation.

\section{UV-Vis analysis}

The influence due to the presence of PSS in the reduction process was analyzed also by monitoring AA:PSS:GO w/w ratio dependent UV-Vis spectroscopy. The $\mathrm{GO}_{\mathrm{A}}$ aqueous dispersion in Fig. 7a showed an absorption peak at $225 \mathrm{~nm}$ attributed to $\pi-\pi^{*}$ transitions of aromatic $\mathrm{C}=\mathrm{C}$ bonds and a shoulder peak at about $300 \mathrm{~nm}$ attributed to $n-\pi^{*}$ transitions of $\mathrm{C}=\mathrm{O}$ bonds ( $\mathrm{Li}$ and $\mathrm{Liu}$ 2010). The $\mathrm{GO}_{\mathrm{B}}$ solution exhibited a similar peak at $229 \mathrm{~nm}$, the higher wavelength being indicative of more $\pi-\pi^{*}$ transitions. The AA 


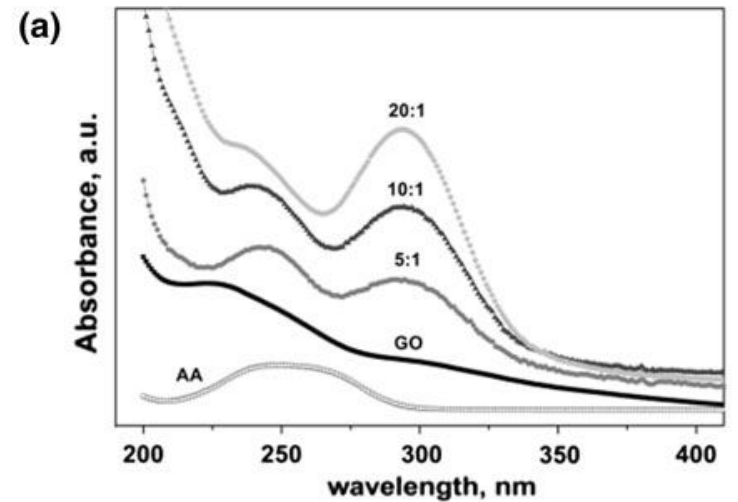

(b)

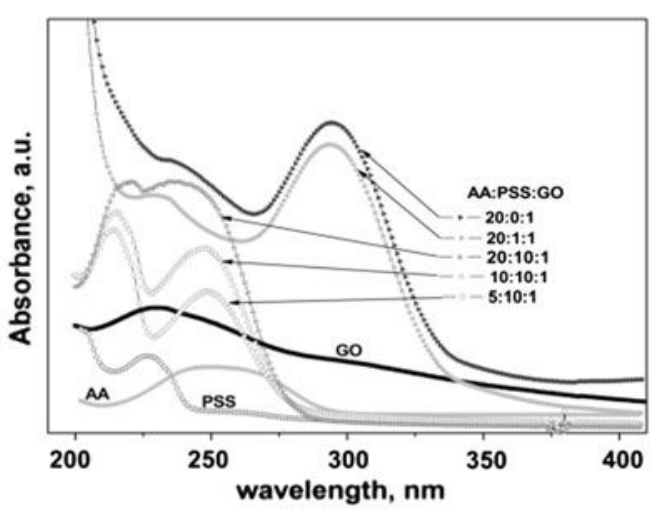

(c)

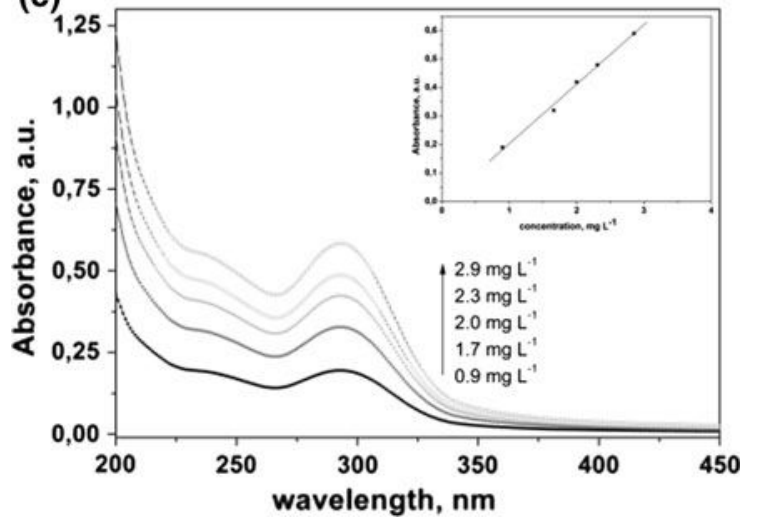

Fig. 7 UV-Vis absorption spectra of: a $\mathrm{GO}_{\mathrm{A}}$ and $\mathrm{rGO}_{\mathrm{A}}$ aqueous dispersions as a function of $\mathrm{AA}: \mathrm{GO}_{\mathrm{A}} \mathrm{w} / \mathrm{w}$ ratio and b $\mathrm{GO}_{\mathrm{B}}$ and PSS- $\mathrm{rGO}_{\mathrm{B}}$ solutions for different AA:PSS:GO w/w ratio, $\mathbf{c} \mathrm{rGO}_{\mathrm{A}}$ aqueous dispersions at different concentrations (inset: relationship between the absorbance and concentration)

absorption peak was centred at $250 \mathrm{~nm}$. In agreement with $\mathrm{XRD}$ results, the $\mathrm{GO}_{\mathrm{A}}$ peak red-shifted to 235-240 nm upon reduction and the shoulder peak shifted to 290-294 nm suggesting restoration of electronic conjugation within the graphene sheets upon reduction with AA. The intensity of characteristic peak of $\mathrm{rGO}_{\mathrm{A}}$ increased with the increasing

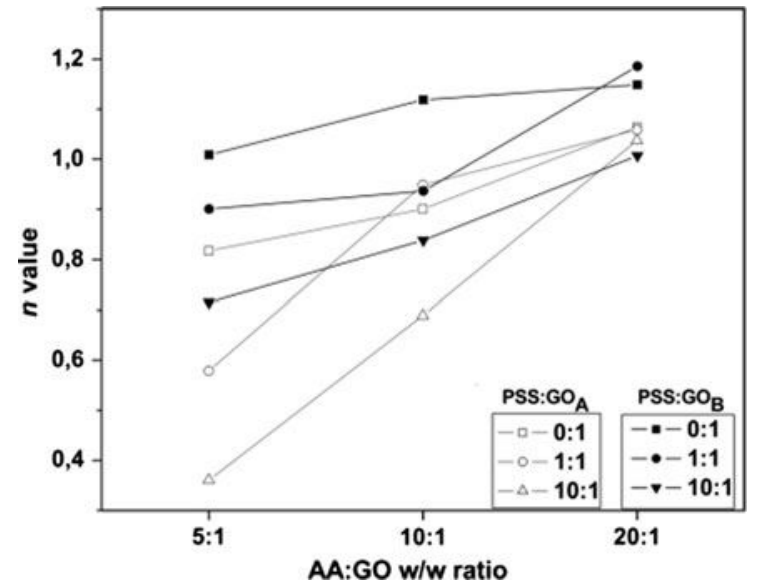

Fig. 8 The reduction efficiency of PSS-rGO by AA ( $n$ value) as a function of graphite oxidation parameters, PSS:GO and $\mathrm{AA}: \mathrm{GO} \mathrm{w} / \mathrm{w}$ ratio

amount of the reducing agent (this aspect is further discussed below), but there was no any significant increase in absorption wavelength or absorption intensity with prolonged reaction time, indicating limiting reduction rate after $24 \mathrm{~h}$.

The reduction process of PSS-functionalized GO was evaluated as a function of AA:PSS:GO weight ratio. One can observe from Fig. $7 \mathrm{~b}$ that $\mathrm{rGO}_{\mathrm{B}}(20: 0: 1)$ shows two absorption peaks similar to $\mathrm{rGO}_{\mathrm{A}}$ - the one at $240 \mathrm{~nm}$ ascribed to the $\mathrm{GO}_{\mathrm{B}}$, and the second at $290 \mathrm{~nm}$ ascribed to $\mathrm{rGO}_{\mathrm{B}}$. With increasing PSS:GO $\mathrm{G}_{\mathrm{B}}$ ratio, the corresponding spectra presents a blue-shifted peak attributed to new material alone because the solution of pure PSS did not show any absorption at that wavelength and therefore confirming the successful attachment of PSS molecules to the GO material. Moreover, all rGO solutions showed a good linear relationship between the absorbances, at 290 and $250 \mathrm{~nm}$, respectively, and the concentrations of rGO, confirming that the solutions obey Beer's law and rGO sheets disperse well in water-for exemplification see Fig. 7c.

Independent of the initial parameters for the oxidation of graphite, the UV-Vis absorption spectra presented similar trends as seen in Fig. 7, such as wavelength-shifts for rGO, PSS-rGO, peak intensity, and corresponding wavelength-shift of PSS-rGO with PSS functionalization. These facts show that even if the properties of GO are variable due to the uncontrollability of the oxidation reaction, they present similar characteristics by UV-Vis monitoring. 
Fig. 9 Reduction mechanism of GO in presence of PSS by AA

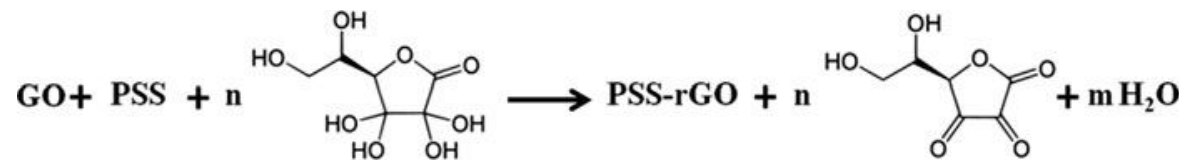

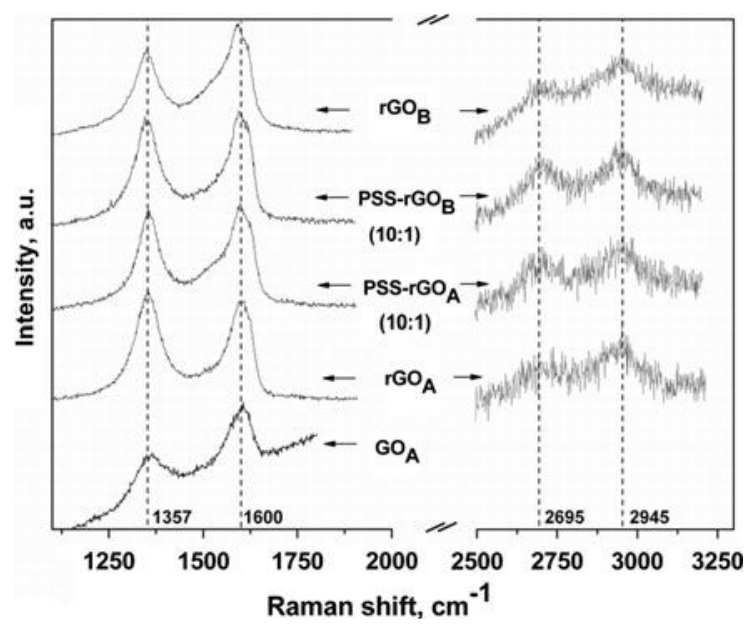

Fig. 10 Raman spectra of GO, rGO and PSS-rGO materials

The intensity ratio between the absorption peaks corresponding to rGO materials and GO was calculated as a first approximation $\left(n=I_{\mathrm{rGO}} / I_{\mathrm{GO}}\right)$ for the reduction process efficiency, and the obtained values are presented in Fig. 8. For both types of GO, the $n$ value for rGO dispersions increased with the amount of reducing agent (as observed in Fig. 7a, b), with the reduction being more evident for $\mathrm{GO}_{\mathrm{A}}$ materials. However, these results are only indicative of the effect of increasing ratio of surfactant and reducing agent, respectively, and not on the reduction process, since not only the composition of GO materials is different, but also the spatial arrangement of oxygen species, which interact affecting the spectral response upon reduction (Boehm 1994).

Evaluation of the effect of PSS amount on the reduction process showed that $n$ value for functionalized rGO generally decreased with increasing PSS amount, independent of the AA:GO w/w ratio. During the chemical functionalization process, PSS is expected to be adsorbed onto the surface of the GO nanosheets and further prevent them from agglomeration during the reduction process, but the existing functionalities in the GO sheets play a very important role under this aspect as explained below. The carbonyls at the edges of GO sheets are generally isolated or in a quinone-like arrangement (two neighboring carbonyl groups) that represents the most stable oxygen configuration. Next to a hydroxyl neighbor (enolic groups) and another adjacent carboxyl group, repulsive forces are generated, which stabilize the groups (Li et al. 2008; Szabó et al. 2006). Such functional groups influence the selective molecular intercalation or the adsorption of molecules, leading to a variety of covalent modifications. Both $\pi-$ $\pi$ stacking and van der Waals interaction that could lead to its adsorption were primarily responsible for the PSS binding to the nanosheets (Stankovich et al. 2006).

As reducing agent amount increased, a higher $n$ value was obtained for the PSS-rGO, independent of the amount of PSS. The increase of $n$ value is more evident in case of PSS- $\mathrm{rGO}_{\mathrm{A}}$ independent of PSS amount, suggesting a higher reduction rate for the GO obtained from harsher oxidation conditions (A). As TGA results show that $\mathrm{GO}_{\mathrm{A}}$ has more labile oxygen groups than $\mathrm{GO}_{\mathrm{B}}$, it is believed that in case $\mathrm{B}$, after removal of these groups, the remnant ones are more difficult to remove, the fact that slows the reduction rate. Therefore, it is suggested the UV-Vis results are dependent not only on PSS attachment but also on the labile oxygen functionalities in the GO sheets. It is also known that the edge plane carboxyl groups are highly unstable, whereas carbonyl groups are more difficult to remove (Ganguly et al. 2011).

\section{Mechanism of reduction}

As for the mechanism of the chemical reduction of GO by $\mathrm{AA}$, this is still an open question. $\mathrm{AA}$ is known to release two protons to form dehydroascorbic acid (Hancock and Viola 2005). The protons have high binding affinity to some oxygen functionalities, such as hydroxyl and epoxide groups, attached to the GO basal planes to form water molecules (Davies et al. 1991). Therefore, the overall equation could be written as given in Fig. 9, where $n$ and $m$ coefficients depend on the stoichiometry of GO and where the final product PSS-rGO is most probably obtained through more intermediates. 
Fig. 11 a SEM image of dry graphite oxide type A b TEM and corresponding SAED pattern of rGOA c TEM image of PSS-rGOA and $\mathbf{d}$ AFM image and section analysis of $\mathrm{rGO}_{\mathrm{A}}$ sheets
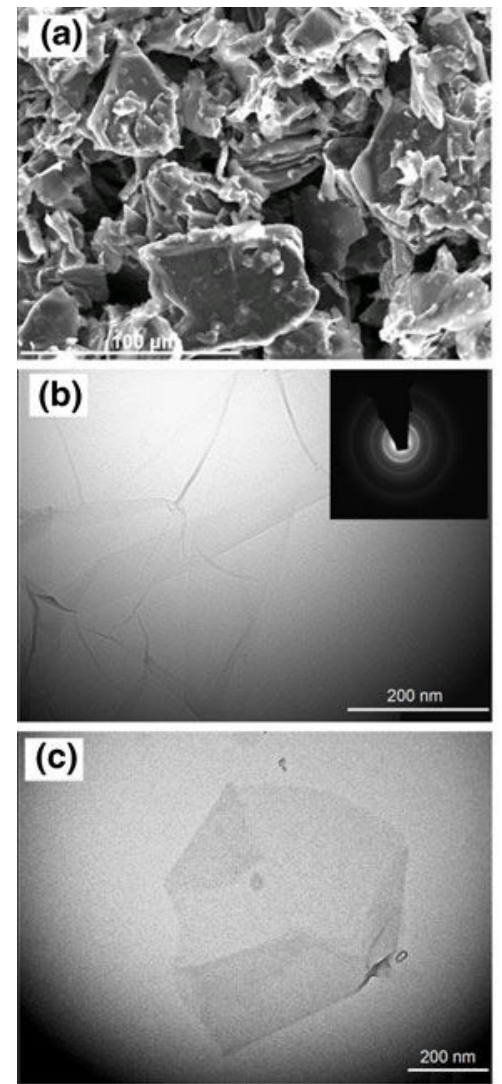

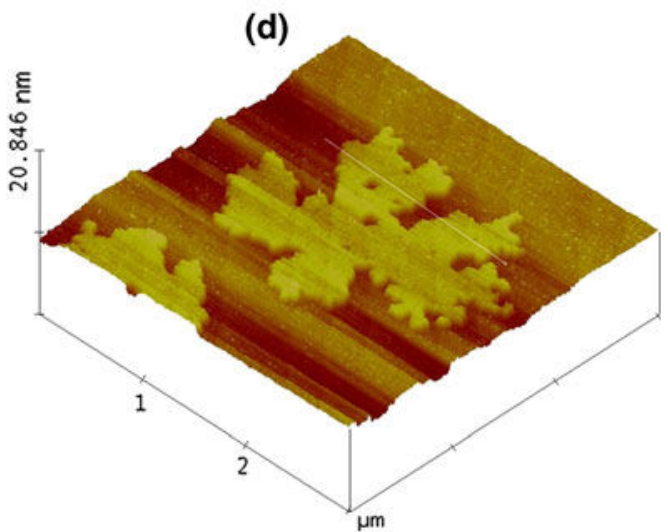

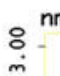

Section Analysis
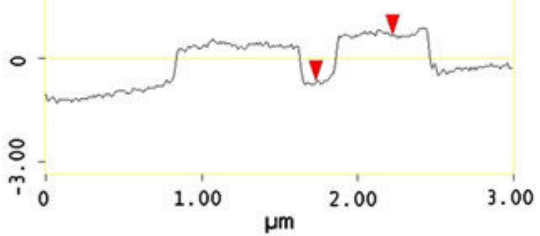

\section{Raman spectroscopy}

The electronic structure-sensitive technique of Raman spectroscopy usually reveals a strong $\mathrm{G}$ band around $1,575 \mathrm{~cm}^{-1}$ related to the vibration of $s p^{2}$-bonded carbon atoms; a weak D band around $1,340 \mathrm{~cm}^{-1}$ associated with structural imperfections of graphene sheet and disorders (vacancies and grain boundaries), edges, and amorphous carbon species; and a 2D band around $2,700 \mathrm{~cm}^{-1}$ for pristine graphite (Ferrari et al. 2006; Kim et al. 2009).

For our $\mathrm{GO}_{\mathrm{A}}$ material, the Raman spectrum in Fig. 10 displayed a D band at $1,360 \mathrm{~cm}^{-1}$ and a blueshifted $\mathrm{G}$ band to $1,600 \mathrm{~cm}^{-1}$ possibly due to the presence of defects. The prominent $\mathrm{D}$ band is indicative of significant structural disorder due to the extensive oxidation. Because of high percentage of $s p^{3}$ defects in oxidized material, the higher $I_{\mathrm{D}} / I_{\mathrm{G}}$ observed in rGO materials proves a decrease in the average size but an increase in the number of $s p^{2}$ domains upon reduction.

Interestingly, in spite of noisy spectra, two small peaks were observed for all rGO materials: a 2D band sensitive to the aromatic C-structure at around $2,695 \mathrm{~cm}^{-1}$ and an additional peak at $2,945 \mathrm{~cm}^{-1}$ ascribed to the $\mathrm{G}+\mathrm{D}$ combination mode induced by disorder or the $\mathrm{D}+\mathrm{D}^{\prime}$ band (Elias et al. 2009). As expected, the $\mathrm{rGO}_{\mathrm{B}}$ materials showed higher $I_{2 \mathrm{D}} / I_{\mathrm{G}}$ and $I_{2 \mathrm{D}} / I_{\mathrm{D}+\mathrm{G}}$ values than $\mathrm{rGO}_{\mathrm{A}}$. The higher $I_{2 \mathrm{D}} / I_{\mathrm{D}+\mathrm{G}}$ obtained for reduced materials in presence of PSS are indicative of efficient attachment of PSS molecules towards the restoration of aromatic C-structure, although the recovery of $s p^{2}$ lattice is lower than for other methods such as introducing carbon radicals while thermally reducing the GO (Dai et al. 2011).

\section{Morphology}

The microscopy analysis revealed randomly aggregated, crumpled sheets for the dry graphite oxide material-see SEM image in Fig. 10a. The TEM images in Fig. 10b and c depict exfoliated $\mathrm{rGO}_{\mathrm{A}}$ and PSS- $\mathrm{rGO}_{\mathrm{A}}$ as large transparent folded sheets of few hundred square nanometers resembling silk veil waves while the selected area diffraction pattern (SAED) 
indicated an amorphous structure for the $\mathrm{rGO}_{\mathrm{A}}$ material in agreement with the finding that harsher oxidation conditions could result in amorphous reduced graphite oxides (Mkhoyan et al. 2009).

The AFM characterization revealed various shapes and sizes of GO sheets with an average thickness of folded sheets of around $2 \mathrm{~nm}$. They are expected to be "thicker" than graphene because of the presence of covalently bonded oxygen and the displacement of the $s p^{3}$-hybridized carbon atoms slightly above and below the original graphene plane. It is also admitted that sonication treatment affects greatly the exfoliation of obtained GO materials. As for rGO, sheets with average area of $4 \mu \mathrm{m}^{2}$ and thickness around $1.1 \mathrm{~nm}$ were observed (see the AFM image of $\mathrm{rGO}_{\mathrm{A}}$ in Fig. 11d). This value is smaller than for GO but still much larger than the interplanar space of the natural graphite and it could be explained by the remaining functionalities within the rGO planes.

\section{Conclusions}

In this study, reduction of PSS-functionalized GO nanosheets with varying overall amount and type of oxygen functionalities have been prepared following a green approach using AA. A higher dispersibility for rGO obtained from mildly oxidized graphite was observed while PSS assistance was more evident in the case of harsh conditions. The chemical reduction of differently expanded GO materials appears to be an AA diffusion-limited process. Independent of the oxidation conditions, the PSS functionalization corresponding to AA:PSS:GO w/w of 20:10:1 resulted in similar $\mathrm{I}_{\mathrm{D}} / \mathrm{I}_{\mathrm{G}}$, which improved the recovery of $s p^{2}$ lattice.

Although the recovery of the $s p^{2}$ network was only partially achieved in this novel PSS-rGO, the obtained nanosheets retain significant electron-rich $s p^{2}$ domains that can be further used for grafting additional groups, given the importance of functionalization not only for stabilizing the graphene sheets, but also for harvesting the material's full potential in solution-based processes. A multistep process combining green chemical reduction of a mildly oxidized material and a thermal treatment is proposed for a lower defect concentration.

Acknowledgments The authors thank the European Commission for their financial support through the project no. NMP3SL-2010-246073.

\section{References}

Acik M, Lee G, Mattevi C et al (2011) The role of oxygen during thermal reduction of graphene oxide studied by infrared absorption spectroscopy. J Phys Chem C 115:1981-19761

Akhavan O, Ghaderi E (2012) Escherichia coli bacteria reduce graphene oxide to bactericidal graphene in a self-limiting manner. Carbon 50:1853-1860

Akhavan O, Ghaderi E, Esfandiar A (2011) Wrapping bacteria by graphene nanosheets for isolation from environment, reactivation by sonication, and inactivation by near-infrared irradiation. J Phys Chem B 115:6279-6288

Akhavan O, Ghaderi E, Aghayee S, Fereydooni Y, Talebi A (2012) The use of a glucose-reduced graphene oxide suspension for photothermal cancer therapy. J Mater Chem 22:13773-13781

Bae S, Kim H, Lee Y et al (2010) Roll to- roll production of 30-inch graphene films for transparent electrodes. Nat Nanotechnol 5:574-578

Bai H, Xu Y, Zhao L, Li C, Shi G (2009) Non-covalent functionalization of graphene sheets by sulfonated polyaniline. Chem Commun 13:1667-1669

Boehm HP (1994) Some aspects of the surface chemistry of carbon blacks and other carbons. Carbon 32:759-769

Boukhvalov DW, Katsnelson MI (2008) Modeling of graphite oxide. J Am Chem Soc 130:10697-10701

Buchsteiner A, Lerf A, Pieper J (2006) Water dynamics in graphite oxide investigated with neutron scattering. J Phys Chem B 110:22328

Choi BG, Park H, Park TJ et al (2010) Solution chemistry of self-assembled graphene nanohybrids for high-performance flexible biosensors. ACS Nano 4:2910-2918

Cote LJ, Silva RC, Huang J (2009) Flash reduction and patterning of graphite oxide and its polymer composite. J Am Chem Soc 131:11027-11032

Dai B, Fu L, Liao L et al (2011) High-quality single-layer graphene via reparative reduction of graphene oxide. Nano Res 4:434-439

Davies MB, Austin J, Partridge DA (1991) Vitamin C: its chemistry and biochemistry. Royal Society of Chemistry, Cambridge

Elias DC, Nair RR, Mohiuddin TMG, Morozov SV, Blake P, Halsall MP et al (2009) Control of graphene's properties by reversible hydrogenation: evidence for graphene. Science 23:610-613

Fan FRF, Park S, Zhu Y, Ruoff RS, Bard AJ (2009) Electrogenerated chemiluminescence of partially oxidized highly oriented pyrolytic graphite surfaces and of graphene oxide nanoparticles. J Am Chem Soc 131:937-939

Fernandez-Merino MJ, Guardia L, Paredes JI, Villar-Rodil S et al (2010) Vitamin $C$ is an ideal substitute for hydrazine in the reduction of graphene oxide suspensions. J Phys Chem C 114:6426-6432

Ferrari AC, Meyer JC, Scardaci V, Casiraghi C, Lazzeri M, Mauri F, Piscanec S, Jiang D, Novoselov KS, Roth S, Geim AK (2006) Raman spectrum of graphene and graphene layers. Phys Rev Lett 97:187401-187405

Ganguly A, Sharma S, Papakonstantinou P, Hamilton J (2011) Probing the thermal deoxygenation of graphene oxide using high-resolution in situ X-ray-based spectroscopies. J Phys Chem C 115:17009-17019 
Hancock RD, Viola R (2005) Biosynthesis and catabolism of Lascorbic acid in plants. Crit Rev Plant Sci 24:167-188

Hernandez Y, Nicolosi V, Lotya M et al (2008) High-yield production of graphene by liquid-phase exfoliation of graphite. Nat Nanotechnol 3:563-568

Hontoria-Lucas C, Lopez-Peinado AJ, Loepz-Gonzalez JDD et al (1995) Study of oxygen-containing groups in a series of graphite oxides: physical and chemical characterization. Carbon 33:1585-1592

Jeong HK, Lee YP, Lahaye RJWE et al (2008) Evidence of graphitic AB stacking order of graphite oxides. J Am Chem Soc 130:1362-1366

Kim KS, Zhao Y, Jang H, Lee SY, Kim JM, Kim KS, Ahn JH, Kim P, Choi JY, Hong BH (2009) Large-scale pattern growth of graphene films for stretchable transparent electrodes. Nature 457:706-710

Kuila T, Bose S, Mishra AK, Khanra P, Kim NH, Lee JH (2012) Chemical functionalization of graphene and its applications. Prog Mater Sci 57:1061-1105

Kuilla T, Bhadra S, Yao D, Kim NH, Bose S, Lee JH (2010) Recent advances in graphene based polymer composites. Prog Polym Sci 35:1350-1375

Kumar P, Subrahmanyam KS, Rao CNR (2011a) Graphene produced by radiation-induced reduction of graphene oxide. Intl J Nanosci 10:559-566

Kumar P, Panchakarla LS, Rao CNR (2011b) Laser-induced unzipping of carbon nanotubes to yield graphene nanoribbons. Nanoscale 3:2127-2129

Kumar P, Das B, Chitara B et al (2012) Novel radiation induced properties of graphene and related materials. Macromol Chem Phys 213:1146-1163

Lee C, Wei X, Kysar JW, Hone J (2008) Measurement of the elastic properties and intrinsic strength of monolayer graphene. Science 321:385-388

Li D, Kaner RB (2008) Graphene-based materials. Science 320:1170-1171

Li J, Liu CY (2010) Ag/Graphene heterostructures: synthesis, characterization and optical properties. Eur J Inorg Chem 8:1244-1248

Li D, Muller MB, Gilje S, Kaner RB, Wallace GG (2008) Processable aqueous dispersions of graphene nanosheets. Nat Nanotechnol 3:101-105

Li X, Cai W, An J et al (2009) Large-area synthesis of highquality and uniform graphene films on copper foils. Science 324:1312-1314

Maitra U, Matte HSRR, Kumar P, Rao CNR (2012) Strategies for the synthesis of graphene, graphene nanoribbons, nanoscrolls and related materials. Chimia 66:941-948

Mei XG, Ouyang JY (2011) Ultrasonication-assisted ultrafast reduction of graphene oxide by zinc powder at room temperature. Carbon 49:5389-5397

Mkhoyan K, Contryman A, Silcox J, Stewart D, Eda G, Mattevi C, Miller S, Chhowalla M (2009) Atomic and electronic structure of graphene-oxide. Nano Lett 9:1058-1063
Nair RR, Blake P, Grigorenko AN et al (2008) Fine structure constant defines visual transparency of graphene. Science 320:1308

Park S, Lee KS, Bozoklu G et al (2008) Graphene oxide papers modified by divalent ions enhancing mechanical properties via chemical cross-linking. ACS Nano 2:572-578

Park S, An J, Jung I et al (2009) Colloidal suspensions of highly reduced graphene oxide in a wide variety of organic solvents. Nano Lett 9:1593-1597

Park HJ, Meyer J, Roth S, Skákalová V (2010) Growth and properties of few-layer graphene prepared by chemical vapor deposition. Carbon 48:1088-1094

Park S, An J, Potts JR, Velamakanni A, Murali S, Ruoff RS (2011) Hydrazine-reduction of graphite- and graphene oxide. Carbon 49:3019-3023

Patil AJ, Vickery JL, Scott TB, Mann S (2009) Aqueous stabilization and self-assembly of graphene sheets into layered bio-nanocomposites using DNA. Adv Mater 21: 3159-3164

Stankovich S, Piner RD, Chen X, Wu N, Nguyen SBT, Ruoff RS (2006) Stable aqueous dispersions of graphitic nanoplatelets via the reduction of exfoliated graphite oxide in the presence of poly(sodium 4-styrenesulfonate). J Mater Chem 16:155-158

Subrahmanyam KS, Panchakarla LS, Govindaraj A, Rao CNR (2009) Simple method of preparing graphene flakes by an arc-discharge method. J Phys Chem C 113:4257-4259

Szabó T, Tombacz E, Illes E, Dékány I (2006) Enhanced acidity and $\mathrm{pH}$-dependent surface charge characterization of successively oxidized graphite oxides. Carbon 44:537-545

Wu JS, Pisula W, Mullen K (2007) Graphenes as potential material for electronics. Chem Rev 107:718-747

Wu H, Zhao WF, Hu HW, Chen GH (2011) One-step in situ ball milling synthesis of polymer-functionalized graphene nanocomposites. J Mater Chem 21:8626-8632

Xu Y, Bai H, Lu G, Li C, Shi G (2008) Flexible graphene films via the filtration of water-soluble noncovalent functionalized graphene sheets. J Am Chem Soc 130:5856-5857

Yin Z, Wu S, Zhou X et al (2010) Electrochemical deposition of $\mathrm{ZnO}$ nanorods on transparent reduced graphene oxide electrodes for hybrid solar cells. Small 6:307-312

Zhang L, Liang J, Huang Y, Ma Y, Wang Y, Chen YS (2009) Sizecontrolled synthesis of graphene oxide sheets on a large scale using chemical exfoliation. Carbon 47:3365-3380

Zhang J, Yang H, Shen G, Cheng P, Zhang J, Guo S (2010) Reduction of graphene oxide via L-ascorbic acid. Chem Comm 46:1112-1114

Zhou Y, Bao Q, Tang LAL, Zhong Y, Loh KP (2009) Hydrothermal dehydration for the 'green' reduction of exfoliated graphene oxide to graphene and demonstration of tunable optical limiting properties. Chem Mater 21:2950-2956 